\title{
PROBLEMS IN . TEACHING THE PRONUNCIATION OF JAPANESE TO ENGLISH-SPEAKING PERSONS
}

\section{Summary}

The tonal character of spoken Japanese makes important demands upon the learner: 1 . He must be trained to discriminate carefully by ear and : : produce in pronunciation the characteristic low, mid and high tones. 2 . The characteristic melody patterns must be learned. 3. Special care must be taken in making smooth transitions from one level of pitch to anotiner while passing from syllable to syllable. 4. He must eliminate the carry-over of English stress accent into Japanese.

Although some attention has been given in recent years to the teaching of the pronunciation of the Japanese language to Englishspeaking people, there is still opportunity to improve both method and practice. The problems discussed in this paper fall into four groups: 1 . aural and oral training in pitch variations; 2 . difficulty in acquiring the melody patterns; 3 . acquisition of skill in making the tiansitional junctures between syllables; 4 . distortion caused by the imposition of Englisin stress accent.

1. In infancy and childhocd, during the acquisition of the vernacular, an individual learns to control the basic elements of pronunciation. Japanese accent being tonal, the Japanese child undergoes continuov.s training in the auditory discrimination and pronunciation of different degrees of pitch, low, mid and high, which we may illustrate as follows: haná ') (flower), hanâ (nose); hashi (bridge), háshi (chopsticks), hashi (edge).

The English-speaking person, in studying Japanese pronunciation, must acquire two skills in order to pronounce the Japanese pitch variations correctly: (1) the ability to discriminate aurally the difference between tones and (2) the ability to reproduce them orally.

Careful measurement of the accuracy of pitch discrimination shows that about $85 \%$ of the average run of Americans can distinguish

1) In this paper the sign of the high pitch is indicated by the usual sign of the acute accent; mid pitch is indicated by the same sign doubled; low pitch is left unmarked. For the definitions of "high", "mid" and "'ow" see Shohara, Lingua, Vol. I (1948), p. 408. 
a pitch of 215 vibrations per second (which is approximately the pitch of $A$ below middle C) from 216 when the notes are sounded in succession as they are in the syllables of words. Since the average difference between low and high pitch in Japanese is about $34^{2}$ ) vibrations per second in the range of pitch falling in the scale just

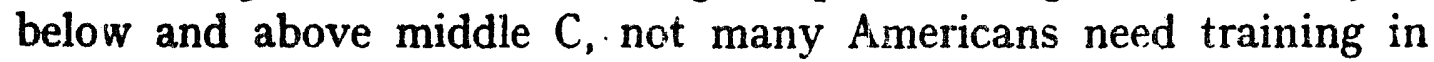
disc:imination once their attention is called to it. However, since in spoken English there are no such systematic variations in pitch, they must be trained to reproduce these differences. The average individual is alble to discriminate between tones with two or three times the accuricy with which he can produce thern ora.lly. For this reason special emphasis must be laid upon training in fluency of oral reproduction. Spontaneous and automatic reproduction of the characteristic Japanese intonation is attained only by intensive drill. Aural and oral training must go hand in hand. The writer does not agree with those who maintain that, if the student can hear foreign sounds correctly, he can, automatically, produce them correctly.

It is assumed that accurate pronunciation of a foreign language requires imitation of the pronunciation of a teacher or an informant or of accurate phonograph records. In teaching individuals who have little appreciation of musical tone, the first step is to train the ear to recogrize the characteristic musical tones of Japanese. This can be accomplished by first explaining and illustrating these characteristic tones and then subjecting the class to intensive drill in the imitation of the uifferent types of variations as pronounced by the teacher, using as far as possible, brief sentences of only one or few words, or phrases which in specific situations serve as substitutes for complete sentences. Progressive modern language teachers are agreed that in general $\mathbf{i}$ : is inefircient to begin instruction in foreign angua jes with individual is lated words rather than with connected discourse. However, it is expredient at times in pronunciation drill to make use also of isolated words as sup olementary material $\left.{ }^{3}\right)$. An illustration will show how word accent is nodified in sentences. In the pronunciation of hon (book), which the Japanese treat as a two-syllable word, the first syllatle ho has a high tone and the second syllable $n$ as a low

s) Op. cit. p $407 f$.

3) Japanese Pronunciation Drill, The Japanese Language :chool, University of Michigan, 1945. 
tone. In the word k:n $\delta$ (this), ko has a low tone and the second syllable $n o$ the mid tone. When, however, in connected discourse, kono is followed by hon, the no in kono is raised in pitch and the ho of hon is lowered so that the two approach each other in tone, but (and this is importar $t$ ) the relative pitches of the two syllables of each word remain unchanged in the sense that the higher pitched syllable in the isolated word remains the higher pitched syllable in connected discourse. It should be remembered that the differences between these three degrees are relative and not absolute. Moreover the pitch level varies writh different individuals. For example, the conversational voice of one female subject ranged from 150 to 235 vibrations per second while the voice of another ranged from 183 to 315 vibrations per second.

2. There a.re various frequently occurring patterns of intonation with which the teacher should familiarize the student. Typical examples are:

(1) Brief sentences of the type, Arigato(o) gozaimasu. (Thank you,), Isogashii ndesu. (I am busy.), Chikai ndesiu. (It's near.) have as a distinctive characteristic a low or mid-low initial syllable followed by a mid pitchec or a high pitched syllable after which the pitch falls steadily toward the end.

(2) Another common type of Japanese sentence is characterized by a combination of words and phrases of two or even several syllables of approximattly equal pitch and stress. Examples are: Kashikomarimashita. (Yes, certainly.), Gobusata-itashimashita. (I have neglected calling on you.), Okagesama dc.... (Thanks to you....). An approximately co-rect pronunciation of this type can usually be attained by the student if he is instructed to pronounce such group of words with approximately even stress without variation of pitch. Must students can attain this, since it is a natural physiological habit of Englishspeaking people, that pitch varies in the same direction as the stress.

(3) The melody patterns of questions are the same as those of corresponding statements. A question is indicated by the particle $k a$ (low, mid or high) at the end of the sentence.

Other melody patterns such as those of requests and exclamations should be drilled 4).

1) All types of :ertence intonation are represented in Introductiun to Spoken Japanese, University of Michigi.n, unpublished. 
3. The third problem requiring special attention concerns the transitional novements (and resulting sounds) made in passing from syllable to syllable. We may call these transitions "junctures" and arbitrarily limit each juncture to a period of six hundredths of a second ${ }^{5}$ ). In Japanese every syllable consists of either a single vowel or of a single consonant followed by a vowel. This peculiarity almost entirely excludes the immediate juxtaposition and blending of two consonants sio common in English ${ }^{6}$ ). Juncture is characterized by an extensive overlapping of two different groups of muscular movements causing a blending of two successive sounds. This phenomenon occurs in all languages to a greater or less extent. Japanese, however, has one peciliarity which presents a special problem to the teacher. Statistical data obtained from extensive kymograph records of the junctures of spoken Japanese syllables show that during the transitional period 1 ere was a fall in pitch in $29 \%$ of the cases; a rise in pitch in $13 \%$ and a level pitch ir $58 \%$, that is, in ?.pproximately six tenths of the 343 junctures studied. This was true not only of those syllables in the cases of which th' average pitch of the successive syllables is apr roximately equal, but also true in those cases in which the "standard" pitches of the successive syllables differ by a considerable amount even as much as 60 vibrations per second, a difference about equal to that between middle $C$ and the $G$ below it. The Englishspeaking student of Japanese fincis a serious difficulty in so "scftening' his pronun ciation of consonants as to secure this smoothness of transition. This levelness of junctures, while hardly perceptible to the ear of those not musically trained, evidently contributes to the smooth transition rom syllable to syllable. This frequently occurring characteristic lev lness of junctures along with a likewise frequently recurring level stress of syllables as a whole contributes to the production of an effect of evenness and smoothness, which stands in contrast to the sharpness which the pronounced stress accent gives to English.

4. Our last problem, which is concerned in part with stress, is closely related to the foregoin $\xi$ problems, since, in Japanese as a tonal

s) In ou: material the Japanese syllable in the Tokyo dialect averages about fifteen hur:dredths of a second in length.

b) Signi ïcance of Overlapping Movements in Speech, H. Shohara, Proceedings of the Second Biennial Central Zone Conference of the A rierican Society for the Hard of Hearing, St. Louis, Mo., 1939. 
language, the prominence of variation in tone implies less promintace of the element of stress in the pronunciation of both vowels and consonants. Thus Americans and English, not only have difficulty in appreciating and reproducing Japanese melody, but, in addition, since accent in English is chiefly a matter of varying stress, they tend to distort the Jajlanese intonation by carrying over into Japanese their deeply ingrained habit of varying the loudness of successive syllables and words. Often this imposed stress distorts the pitch pattern and the characteristically level stress of Japanese. The fact that the increased stress in English often involves a rise in pitch enhances this danger. The difficulty can best be overcome, as we believe, by training the learner to avoid variation in loudness, while undergoing intensive drill in pronunciation of isolated words and short phrases selected to illustrate the three basic types of pitch variation in Japanese ${ }^{7}$ ).

Many other specific problems arise in connection with the teaching if Japanese pronuriciation. I have selected the above four as the most fi ndamental.

University of Miikigan, Hide Helen Shohara Ann Arbor, Michigan

7) Japanese Fronu nciation Drill, The Japanese Language Schoc', University of Michigan, $194 !$. 